\title{
BURDEN OF DEVELOPMENTAL AND BEHAVIORAL PROBLEMS AMONG CHILDREN - A DESCRIPTIVE HOSPITAL BASED STUDY
}

\author{
Hem Sagar Rimal, Archana Pokharel, Vijay Saha, Arun Giri, \\ Basudha Ghimire, Shiva Raja and Bijoy Verghease
}

\begin{abstract}
The child development is a dynamic process that utilizes the genetic potential of the baby to achieve full potential within the context of available environment. Throughout the world, there are growing concerns about developmental, behavioural, social and emotional wellbeing of children. The management of these issues is possible only with an organized approach through a multidisciplinary team
\end{abstract}

\section{Objective:}

To estimate the prevalence of developmental and behavioral disorders in children.

\section{Method:}

Data were collected from primary caregivers of children presented to a developmental and behavioral pediatrics clinic over a period of 12 months. Standard screening and assessment tools like Strength and Difficulty Questionnaire (SDQ), Spence anxiety scale and Vanderbilt rating scale for ADHD were used. Cases were referred to the Psychiatrist, psychologist, speech therapist and physiotherapist for assessment and management when needed.

\section{Results:}

A total of 85 children with developmental problems presented to our clinic which gives clinic prevalence of $8.5 \%$. There were $51(60 \%)$ of male and $34(40 \%)$ of female. The majority of these children were from Morang district 39 (46\%), Sunsari district $13(15 \%)$ and Jhapa District 9 $(10.6 \%)$. The most common diagnosis were speech and language delay $(22.4 \%)$, behavioral problems $21.2 \%$, Anxiety disorders $18.8 \%$, cerebral palsy $14.1 \%$ and Global developmental delay of $11.8 \%$ and several others. The highest number of children i.e 27 (31.8\%), were referred to the psychologist/Psychiatrist followed by speech therapist $25(29.4 \%)$ and physiotherapist 21(24.7\%). Behavioral modification strategies and CBT were provided to children.

Key words: Developmental and behavioral problems, anxiety disorders, Depression, Cognitive behavioral therapy, Behavioral modification strategies.

\section{Introduction}

The child development is a dynamic process that utilizes the genetic potential of the baby to achieve full potential within the context of available environment. Throughout the world, there are growing concerns about developmental, behavioural, social and emotional wellbeing of children. ${ }^{1}$ One of the multicentre study done in 5 developing country including India found the prevalence of self-reported mental health problem as high as $10.5 \%$ with conduct and emotional problems being most common. ${ }^{2}$ Now, all the 
pediatricians have crucial role to play in early diagnosis and management of developmental and behavioral problems in children because they have high prevalence in our region. The management of these issues is possible only with an organized approach through a multidisciplinary team.

\section{Objective}

To estimate the prevalence of developmental and behavioral disorders in children.

\section{Method}

Data for this study were collected during interviews with primary caregivers of children presented to a developmental and behavioral pediatrics clinic at the Nobel Medical College over a period of 12 months. Information was also received from the child as appropriate. We used standard screening and assessment tools like Strength and Difficulty Questionnaire (SDQ), Spence anxiety scale and Vanderbilt ADHD rating scale. Cases were to the Psychiatrist, psychologist, speech therapist and physiotherapist for assessment and management when needed.

The final diagnosis after complete assessment was entered into the database and result was analyzed using standard software (SPSS 16.1) using the Strength and Difficulties Questionnaire (SDQ). The SDQ is an instrument that has been widely used to assess mental health problems, emotional and behavioral problems and strength among children and adolescents ${ }^{3}$. The final conclusion on the presence or absence of mental health problems as measured by SDQ is ideally computed from the combined reports from parents, teachers, and self-report by child ${ }^{4}$. However, self reports may be sufficient screening tool for adolescents aged 11 years or older ${ }^{5}$.

\section{Spence anxiety scale}

The Spence Children's Anxiety Scale was developed to assess the severity of anxiety symptoms broadly in line with the dimensions of anxiety disorder proposed by the DSM-IV. The scale assesses six domains of anxiety including generalized anxiety, panic/agoraphobia, social phobia, separation anxiety, obsessive compulsive disorder and physical injury fears. This measure consists of 44 items; of which 38 reflect specific symptoms of anxiety and 6 relate to positive, filler items to reduce negative response bias.

\section{Vanderbilt ADHD rating scale}

This rating scale includes the 18 ADHD symptoms described in DSM-IV, which are rated on a 4-point likert scale(0-3) that indicates whether each ADHD symptom occurs never(score of 0 ), occasionally(score of 1), often(score of 2) or very often(score of 3). Diagnosis is made based on DSM-IV criteria. It has 9 items that assess inattentive symptoms and 9 items that assess hyperactive and impulsive symptoms. The ADHS Rating Scale has been developed and standardized as a rating scale for children.

\section{Result}

\begin{tabular}{|c|c|}
\hline & \\
\hline Variable & $\mathrm{N}=\mathbf{8 5}(\mathbf{1 0 0 \% )}$ \\
\hline \multicolumn{2}{|l|}{ Gender } \\
\hline Male & $51(60 \%)$ \\
\hline Female & $34(40 \%)$ \\
\hline \multicolumn{2}{|l|}{ Type of family } \\
\hline Nuclear family & $41(48 \%)$ \\
\hline Joint family & $37(43.5 \%)$ \\
\hline Extended/separated family & $7(8.5 \%)$ \\
\hline
\end{tabular}

As shown in Table 1. There were 85 children presented to the hospital which gives clinic prevalence of developmental and behavioral pediatrics problem among children of $8.5 \%$. The mean age of participants in this study was 6 years. Among the participants, male and female children were $51(60 \%)$ and $34(40 \%)$ respectively. The majority of these 
children were from Morang district 39 (46\%) Sunsari district 13 (15\%), Jhapa district 9 $(10.6 \%)$ and $7(8.2 \%)$ were from India. Rest of the children were from Bhojpur, Dhangadhi, Ilam, khotang, Okhaldhunga, Sankhuwasabha, Siraha, Saptari, Terhathum and Udaypur that made total of $17(20 \%)$.

Among those children, $37(43.5 \%)$ of them were from Joint family, 41 (48\%) from nuclear family and rest were from extended family and separated parents.

In this study , 19 (22.4\%) of participants had Language and speech delay, 18 (21.1\%) had behavioral problems , 16 (18.8\%) had anxiety disorder , 14 (16.5\%) had Enuresis, 12 (14.1\%) had cerebral palsy, 12 ( $14 \%)$ had intellectual disability including learning difficulties, $10(11.8 \%)$ had seizure disorder, $10(11.8 \%)$ had Global developmental Delay(GDD), 9 (10.6\%) children had Autism Spectrum Disorder(ASD), 8 ( $10 \%)$ had ADHD, 7 (8.2\%) had adjustment problem,4 (4.7\%) had depression,12 (14.1\%) had cerebral palsy, $8(9.4 \%)$ had conversion disorder, 7 (8.2\%) each had Recurrent abdominal pain and Tics. There were only $3.5 \%$ cases of child abuse and $4(5.9 \%)$ had suicidal ideation. Table 2, shows the data about referral of patients to various Departments.

Table 2: Diagnosis using different tools And clinical evaluation

\begin{tabular}{|l|l|}
\hline Diagnosis & $\begin{array}{c}\text { Number } \\
\text { (percentage) }\end{array}$ \\
\hline $\begin{array}{l}\text { Speech and language } \\
\text { problems }\end{array}$ & $19(22.4 \%)$ \\
\hline Behavioral problems & $18(21.2 \%)$ \\
\hline Anxiety disorders & $16(18.8 \%)$ \\
\hline Enuresis disability & $14(16.5 \%)$ \\
\hline Cerebral Palsy & $12(14.1 \%)$ \\
\hline $\begin{array}{l}\text { Intellectual learning } \\
\text { including } \\
\text { difficulties }\end{array}$ & $10(11.8 \%)$ \\
\hline Seizure disorder & $10(11.8 \%)$ \\
\hline $\begin{array}{l}\text { Global Developmental } \\
\text { delay }\end{array}$ & \\
\hline
\end{tabular}

\begin{tabular}{|l|c|}
\hline $\begin{array}{l}\text { Autism Spectrum } \\
\text { disorder(ASD) }\end{array}$ & $9(10.6 \%)$ \\
\hline $\begin{array}{l}\text { Attention Deficit Hyper } \\
\text { activity Disorder }\end{array}$ & $8(10 \%)$ \\
\hline Conversion disorder & $8(10 \%)$ \\
\hline Adjustment problem & $7(8.2 \%)$ \\
\hline $\begin{array}{l}\text { Recurrent abdominal } \\
\text { pain }\end{array}$ & $7(8.2 \%)$ \\
\hline Tics & $7(8.2 \%)$ \\
\hline Child abuse & $3(3.5 \%)$ \\
\hline Suicidal ideation & $5(6 \%)$ \\
\hline
\end{tabular}

The highest number of children i.e 27 $(31.8 \%)$, were referred to the psychologist/Psychiatrist followed by speech therapist $25(29.4 \%)$, physiotherapist $21 \quad(24.7 \%)$, Otorhinolaryngologist 12 (14.11\%) and Ophthalmologist 8 (9.4\%). Table 3, shows the analyzed data regarding the intervention services provided to those children. Behavioral modification strategies were provided to $14(16.4 \%)$ and Cognitive behavioral therapy were provided to $13(15 \%)$ children.

Table 3: Professionals involved in the care of children

\begin{tabular}{|l|l|}
\hline \multicolumn{1}{|c|}{ Professional } & $\begin{array}{l}\text { Number of cases } \\
\text { seen(percentage) }\end{array}$ \\
\hline $\begin{array}{l}\text { Psychiatrist/Psycholog } \\
\text { ist }\end{array}$ & $27(31.8 \%)$ \\
\hline Speech pathologist & $25(29.4 \%)$ \\
\hline Physiotherapist & $21(24.7 \%)$ \\
\hline Otorhinolaryngologist & $12(14.11 \%)$ \\
\hline Ophthalmologist & $8(9.4 \%)$ \\
\hline
\end{tabular}

\section{Discussion}

Over the past decades the public health relevance of mental health conditions in children and adolescents has been of growing concern for everyone ${ }^{6}$. In this study the prevalence of developmental- behavioral problems in children is $8.5 \%$ which is comparable to the study done in another multicentre study done in 5 developing country including India found the prevalence of self -reported mental health problem as 
high as $10.5 \%$ with conduct and emotional problems being most common ${ }^{2}$.

Speech and language problem was found to be the most common problem which was $25.8 \%$, followed by behavioral problem $21.2 \%$, anxiety disorder of $18.8 \%$ and cerebral palsy of $14.1 \%$. These findings are comparable to the findings of a study done in India by Nair et $\mathrm{al}^{7}$. In a study, based in a rural, socio-economically disadvantaged area of South Africa, aimed to examine the prevalence of children's psychological problems found the prevalence of anxiety/depression being 14\% and this study has higher prevalence $(18.8 \%)$ than this study which may be due to undue stress in school and home environment ${ }^{8}$. There is a consensus opinion that children and adolescents living with adversities and the experience of psychosocial difficulties are more vulnerable to have psychological and behavioral problems. But these inferences are mostly taken from the researches done in affluent and developed countries ${ }^{9-11}$.

The prevalence of Attention Deficit Hyperactivity Disorder (ADHD ) was reported to be $10 \%$ which is comparable to one of the study conducted by national center for health statistics in the year 2007 in USA where parent reported diagnosed prevalence of ADHD for all the children ages 6-17 years was $8.2 \%(95 \% \mathrm{CI} 7.7-8.7)^{12}$. Another study done in Mumbai ,India in preschool children and the prevalence was noted to be $12.2 \%{ }^{13}$.

In this study $10 \%$ of children were diagnosed with Autism spectrum disorder which is higher than the findings of US Centre for Disease Control (CDC) reporting that the autism prevalence rate in 2008 in 8year-old US children was 1 in $88^{14}$. The Prevalence of conversion disorder is lower in our study $10 \%$ vs $14.3 \%$ in the study done at Institute of Medicine, Teaching hospital by Chapagain ,Manisha et $\mathrm{al}^{15}$. The recurrent abdominal pain was found in $8.2 \%$ of children which is lower than the findings from a large, population-based, cohort study, (The Avon Longitudinal Study of Parents And Children where prevalence RAP was found to be $11.8 \%$ of 6 years old children ${ }^{16}$.

Developmental-Behavioral pediatrics (DBP) practice relies heavily on a team approach to blend pediatrics, mental health, and allied health that includes psychologist, speech therapist , physiotherapist and occupational therapist $^{17}$. In this study we referred very high number of cases $27 \quad(31.8 \%)$ to psychologist and $23(25.8 \%)$ to the speech therapist. In a study done among Australian pediatrician, it was noted that their management choices included referral to a multidisciplinary team $(16 \%)$, referral elsewhere $(10 \%)$ and manage alone $(7 \%)^{18}$. The higher rate of referral in our center is probably due to higher prevalence of cases of anxiety disorders, behavioral problems, Speech and language delay.

The adequate functional development of children during infancy and early childhood period reflects the potential for the central nervous system of children for later development. Hence early detection of these problems and appropriate early intervention will improve the outcomes of children with developmental impairments ${ }^{19}$. Counseling services was offered to the parents, speech therapy and physiotherapy for the children who needed these services. Behavioral modification strategies were suggested to $16.4 \%$ of children with behavioral problems .There is plenty of evidence to support that cognitive behavioral therapy is a very important modality of management of anxiety disorders and depressive illness. In this study $21.2 \%$ of children received Cognitive behavioral therapy provided by a clinical psychologist.

\section{Conclusion}

In the context of having limited data about developmental and behavioral pediatrics 
problem in Nepali Children, this study has added some data in this area. It has also highlighted the need for pediatricians to be aware of these problems and develop pragmatic approach to such problems through multi-disciplinary team involvement. Further multi center researches are needed to have the estimation of burden of such problems in our country.

\section{References}

1. Blanchard LT, Gurka MJ, Blackman JA. Emotional, developmental, and behavioral health of American children and their families: a report from the 2003 National Survey of Children's Health. Pediatrics. 2006;117(6):e1202-12. Epub 2006/06/03.

2. Atilola O, Singh Balhara YP, Stevanovic D, Avicenna M, Kandemir H. Self-reported mental health problems among adolescents in developing countries: results from an international pilot sample. Journal of developmental and behavioral pediatrics. 2013;34(2):129-37. Epub 2013/02/02.

3. G. R. The Strengths and Difficulties Questionnaire: a research note. Journal of child psychology and psychiatry, and allied disciplines. 1997(38):581-6.

4. Goodman R MH, Bailey V. The Strengths and Difficulties Questionnaire: a pilot study on the validity of the self-report version. Eur Child Adolesc Psychiatry. 1998;7:125-30.

5. Muris P MC, van Den Berg F. The Strengths and Difficulties Questionnaire (SDQ): further evidence for its reliability and validity in a community sample of Dutch children and adolescents. . Eur Child Adolesc Psychiatry 2003;12:1-8.

6. Ravens-Sieberer U, Erhart M, Gosch A, Wille N. Mental health of children and adolescents in 12 European countries-results from the European KIDSCREEN study. Clinical psychology \& psychotherapy. 2008;15(3):154-63. Epub 2008/12/31.

7. Nair MK, George B, Padma K, Potti N, Elizabeth KE, Jeyaseelan L. Developmental Evaluation Clinic--CDC experience. Indian pediatrics. 2009;46 Suppl:s63-6. Epub 2009/05/16.
8. Cortina MA, Fazel M, Hlungwani TM, Kahn K, Tollman S, Cortina-Borja M, et al. Childhood psychological problems in school settings in rural Southern Africa. PloS one. 2013;8(6):e65041. Epub 2013/06/19.

9. Barbarin OA RL. Adversity and psychosocial competence of South African children. The American journal of orthopsychiatry. 1999; 69.:319-27.

10. ML. R. Psychosocial adversity and child psychopathology. $\mathrm{Br}$ JPsychiatry Res. 1999;174.:480-93.

11. Hackett R HL, Bhakta $\mathbf{P}$, et al. Life events in a South Indian population and their association with psychiatric disorder in children. Int $\mathrm{J}$ Soc Psychiatry. 2000(46):201-7.

12. Kandyce Larson SAR, Robert S. Kahn, Neal Halfon. Patterns of Comorbidity, Functioning, and Service Use for US Children With ADHD, 2007. Pediatrics. 2011 (127): 462-70.

13. Suvarna BS, Kamath A. Prevalence of attention deficit disorder among preschool age children. Nepal Medical College journal. 2009;11(1):1-4. Epub 2009/09/23.

14. Taylor B, Jick H, Maclaughlin D. Prevalence and incidence rates of autism in the UK: time trend from 2004-2010 in children aged 8 years. BMJ open. 2013;3(10):2013-003219.

15. Manisha Chapagai KMD, Pratiksha Tulachan. A Study Of Psychiatric Morbidty Amongst Children Attending A Child Guidance Clinic At A Tertiary Level Teaching Hospital In Nepal Journal of Nobel Medical College 2013; 2(1:3):55-63.

16. Ramchandani PG, Hotopf M, Sandhu B, Stein A. The epidemiology of recurrent abdominal pain from 2 to 6 years of age: results of a large, population-based study. Pediatrics. 2005;116(1):46-50.

17. Nielsen BA, Baum RA, Soares NS. Navigating ethical issues with electronic health records in developmental-behavioral pediatric practice. Journal of developmental and behavioral pediatrics : JDBP. 2013;34(1):45-51. Epub 2013/01/01.

18. Holt JM, McDowell MJ. Developmentalbehavioural problems in general paediatrics. Journal of paediatrics and child health. 1998;34(3):245-9. Epub 1998/06/20.

19. M. G. The Effectiveness of Early Intervention. 1997:11-2.

Corresponding Address: Dr. Hem Sagar Rimal, Department of Paediatrics, Nobel Medical College, Phone No.:- 9851141474, E-mail: hemsagarr@yahoo.com 